\title{
Pancreas and islet cell transplantation
}

Rita Bottino, PhD[Assistant Professor of Pediatrics],

Division of Immunogenetics, Diabetes Institute, Department of Pediatrics, Rangos Research Center, Children's Hospital of Pittsburgh, University of Pittsburgh, School of Medicine, Pittsburgh, PA 15213, USA

Massimo Trucco, MD[Hillman Professor of Pediatric Immunology], Division of Immunogenetics, Diabetes Institute, Department of Pediatrics, Rangos Research Center, Children's Hospital of Pittsburgh, University of Pittsburgh, School of Medicine, Pittsburgh, PA 15213, USA

\section{A. N. Balamurugan, PhD[Research Associate, Department of Surgery], and Department of Surgery, Thomas E. Starzl Transplantation Institute, University of Pittsburgh, School of Medicine, Pittsburgh, PA 15213, USA}

Thomas E. Starzl, MD, PhD[Professor of Surgery]

Department of Surgery, Thomas E. Starzl Transplantation Institute, University of Pittsburgh, School of Medicine, Pittsburgh, PA 15213, USA

\section{Abstract \\ Currently, for the patient with type 1 diabetes, a definitive treatment without resorting to the use of exogenous insulin can be achieved only with pancreas or islet cell transplantation. These means of restoring $\beta$-cell mass can completely maintain essentially normal long-term glucose homeostasis, although the need for powerful immunosuppressive regimens limits their application to only a subgroup of adult patients. Apart from the shortage of donors that has limited all kinds of transplantation, however, the widespread use of $\beta$-cell replacement has been precluded until recently by the drawbacks associated with both organ and islet cell transplantation. Although the study of recurrence of diabetes has generated attention, the fundamental obstacle to pancreas and islet transplantation has been, and remains, the alloimmune response. With a better elucidation of the mechanisms of alloengraftment achieved during the last 3 years, the stage has been set for further advances.}

\section{Keywords}

type 1 diabetes; autoimmunity; allorejection; immunosuppression; tolerance

\begin{abstract}
The different aetiological types of diabetes mellitus are designated type 1, type 2 and other specific types. ${ }^{1}$ Type 1 diabetes is characterized by $\beta$-cell destruction and the requirement of insulin treatment for survival. Type 2 diabetes is a metabolic disorder due to an interplay between dysfunctional insulin production and impaired periphor response. The other forms of impaired glucose homeostasis can be due to different genetic defects, destruction of the exocrine pancreas or malfunction of other endocrine organs. ${ }^{1}$
\end{abstract}

(C) 2002 Elsevier Science Ltd. All rights reserved Ltd.

*Address for correspondence: Children's Hospital of Pittsburgh, Rangos Research Center, 3460 Fifth Avenue, Pittsburgh, PA 15213, USA. 
In 1997 the number of people affected by diabetes mellitus was approximately 130 million worldwide, with an overwhelming preponderance of type 2 (>90\%). For multiple reasons, it is estimated that the total will reach 220 million by the year $2010 .^{2}$ The rise is not expected to be homogeneously distributed. For example, changes in lifestyle in 'recently modernized' parts of the world (e.g. Asian and African countries) will probably result in

disproportionately higher increases in diabetes. In contrast, the fraction of type 1 diabetes is expected to increase over time in developed countries where longer survival after diagnosis results from greater availability of sophisticated care. Relative to the Caucasian population, the incidence of, and the genetic susceptibility to, diabetes and its complications, selectively target ethnic groups such as African-Americans, Hispanic-Americans and Native Americans. ${ }^{3-5}$

Despite improvements in care, the life expectancy of victims of diabetes is at least 10 years shorter in the United States than that of the rest of the population. ${ }^{3}$ Cardiovascular disease, end-stage renal disease and diabetic retinopathy are the major morbidity factors in diabetic people. ${ }^{5-7}$ One-third of all type 1 diabetic individuals have one or more lethal or life-ruining complications that are directly attributable to the underlying diabetes.

The prevention of these and other complications has been improved by technologies that allow the accurate monitoring of blood sugar and/or more flexible administration of appropriate quantities of insulin (i.e. intensified therapy). The Diabetes Control and Complication Trial (DCCT) has examined the impact of glycaemic control on the early occurrence of microvascular, neuropathic and macrovascular complications ${ }^{8}$ in type 1 diabetic patients. These studies demonstrated that intensive insulin therapy with tight glycaemic control could reduce but not completely eliminate the risk for development of some of the most devastating complications.

For the patient with type 1 diabetes, definitive treatment without resorting to the use of exogenous insulin can be achieved presently only with pancreas or islet cell transplantation. These means of restoring $\beta$-cell mass can completely maintain essentially normal long-term glucose homeostasis. Apart from the shortage of donors that has limited all kinds of transplantation, however, the widespread use of pancreas transplantation has been precluded until recently by the imperfections of both organ and islet cell transplantation.

\section{PANCREAS TRANSPLANTATION}

The unresolved problems of pancreas transplantation that were identified from the beginning were both technical and immunological. The immunological category has been the most important, the least understood, and therefore, the most daunting. Rejection has not been the only immune barrier because even recurrence of autoimmune diabetes occurred in recipients of pancreatic grafts. ${ }^{9}$ The fundamental obstacle to pancreas transplantation has been, and remains, the alloimmune response mounted against genetically non-identical donor tissue. The quality of immunosuppression has dictated which of the various operative procedures was adopted. Moreover, the morbidity and mortality inherent in chronic immunosuppression continues even today to influence the selection of recipients.

\section{Immunosuppression}

After the definitive demonstration by Gibson and Medawar ${ }^{10}$ that rejection is an immune reaction, trial and error efforts began in the early 1950s to weaken the allograft recipient response with irradiation and drugs. ${ }^{11}$ As expected, the list of complications from the resulting loss of immune surveillance was a long one that could be divided in two categories: susceptibility to infections and the development of de novo malignancies, in addition, every potent immunosuppressant has its specific toxicity profile. Of the dozens of 
drugs that have been tested clinically, only three have been widely used for continuous baseline therapy: azathioprine ${ }^{12}$, cyclosporine ${ }^{13}$, and tacrolimus. ${ }^{14}$

Dose ranges are available for these immunosuppressants, but for each, and for more recently introduced ones (e.g. sirolimus ${ }^{15}$ and mycophenolate mofetil, $\mathrm{MMF}^{16}$ ), the appropriate dose must be established by trial and error for every transplant recipient. The dose ceilings are imposed acutely by drug toxicity, and the dose floors are revealed by breakthrough rejection. The complex limiting side-effects of the calcineurin inhibitors (cyclosporine and tacrolimus) are of specific interest here, since both cyclosporine and tacrolimus are diabetogenic, nephrotoxic and neurotoxic. Such qualities are not seen with the other T-cell-directed agent, sirolimus, which has its own distinctive panoply of dose-limiting side-effects. ${ }^{15}$

When given after transplantation, none of the foregoing drugs can reliably prevent posttransplant rejection when used alone. However, it was learned in 1962-63 that organ rejection could readily be reversed by adding large doses of prednisone to primary azathioprine treatment, and that the subsequent dose requirements of both azathioprine and prednisone (the 'double-drug cocktail') frequently declined. ${ }^{17}$

In 1966, a short course of antilymphoid globulin (ALG) was added to azathioprine and prednisone (the 'triple-drug cocktail'), with a substantial reduction in maintenance steroid doses. ${ }^{18}$ After validating the efficacy of this 'triple-drug cocktail' in kidney recipients, the first 1-year survival of pancreas recipients was accomplished in June $1969 .{ }^{19}$ The overwhelming mortality with these procedures restricted expansion of organ transplantation for another dozen years. Then, as the more potent cyclosporine and tacrolimus became available, the incidence of acute rejection as well as prednisone-dependence declined, with an increase in survival of all kinds of organ grafts in three distinct leaps over a 40-year period. Thus, the modern history of organ transplantation can be divided into successives eras: (1) azathioprine, (2) cyclosporine and (3) tacrolimus.

During the last decade, pancreas transplantation attained the level of a relatively reliable clinical service, and general agreement was finally reached about a standardized operation. With the definitive elucidation of the mechanisms of alloengraftment during the last 3 years, the stage has been set for further advances in what may be an era 4. Unlike eras 1-3, the impending era 4 may not depend on better immunosuppressants per se, but rather on better timing and more judicious dosing of agents that are already available.

\section{The surgical operations}

The azathioprine era-After surgical technical problems were worked out in the canine model (summarized in ref. 20), Kelly and Lillehei performed the first human operation at the University of Minnesota ${ }^{19}$ on December 17, 1966. Under azathioprine-prednisone immunosuppression, the whole cadaveric pancreas was transplanted to the left iliac fossa of a uraemic recipient after removing the duodenum and ligating the pancreatic duct. A kidney from the same donor was placed in the right iliac fossa. The recipient immediately became insulin-independent, but died at 2 months from a combination of rejection and sepsis. By 1973, Lillehei and Kelly had implanted 13 more whole human pancreas grafts. ${ }^{21}$ Pancreatic secretions of the allografts were either exteriorized (cutaneous graft duodenostomy) or were directed via the graft duodenum into the host jejunum, using a Roux-en Y technique. The only recipient (the 6th) in this pioneer series of 14 cases to achieve long-lasting insulin independence died shortly after reaching the 1 -year milestone with a functioning pancreas after losing the kidney graft and returning to dialysis. The 13 other pancreas graft losses resulted from technical complications, including vascular thrombosis, death with a functioning graft, and most commonly, lethal complications associated with exocrine pancreatic drainage. 
With the premise that the Achilles heel of the operation was exocrine drainage, new strategies emerged to avoid entry into the host bowel for this purpose, to eliminate the donor duodenum from the graft, and to prevent or reduce the volume of the graft secretions. In 1973 , Gliedman et $\mathrm{al}^{22}$ reported excision of the graft duodenum and the adjacent pancreatic head with anastomosis of the segmental pancreatic duct to the recipient ureter. For the next dozen years distal pancreatic segments were used almost exclusively for transplantation.

The cyclosporine era-With the more potent cyclosporine-based immunosuppression the reasons for abandonment of whole-pancreas transplantation were re-examined. The conclusion from this analysis was that transplantation of the whole pancreas (Figure 1) was the best procedure, provided that the allograft exocrine secretions were drained into the host jejunum. In a crucial modification of the original Lillehei procedure, a 'bubble' of duodenum into which the ampulla of Vater emptied was retained with the allograft for anastomosis to the side of the host jejunum (Figure 2).

Two years later, the lowa and Wisconsin teams advocated anastomosis of the bubble to the anterolateral wall of the host bladder rather than the bowel ${ }^{23,24}$ (Figure 3). With diversion of exocrine secretions into the bladder, serial measurement of urine amylase concentration became an accepted means of immune surveillance (i.e. a drop in amylase signalled rejection). However, digestion of the urethra by activated pancreatic enzymes, less serious but highly symptomatic damage to the lower urinary tract, uncorrectable metabolic acidosiscaused by the continuous loss of bicarbonate, and a myriad of other problems necessitating conversion to enteric drainage have diminished enthusiasm for bladder drainage. ${ }^{25}$

The tacrolimus era-The superior control of rejection with minimal dependence on prednisone using tacrolimus-based immunosuppression (era 3) has further eroded the arguments for exocrine diversion to the bladder: i.e. the value of urinary amylase monitoring and of avoidance of an enteric anastomosis. Moreover, it has been possible in simplified tacrolimus-based regimens to eliminate the perioperative induction therapy with ALG or the monoclonal antibody, OKT3, that had become a standard component of immunosuppression during era 2.

\section{Metabolic considerations}

Portal versus systemic insulin release-The venous effluent from a pancreas allograft can be directed by vascular anastomosis into the systemic venous system or into the portal venous bed from where it passes through the liver under normal physiological conditions. Because insulin has important liver-supporting (hepatotrophic) properties ${ }^{26}$ and also because the liver is the primary site of glucose homeostasis, an argument for portal drainage is readily apparent. In practice, however, this has not been an important issue, at least so far. Recipients of portally drained pancreas allografts usually have lower circulating insulin levels than those with the systemic drainage ${ }^{27}$ but no clear difference in metabolic or clinical outcome..$^{28}$

Correction of metabolic deficits-Successful pancreas transplantation results in independence from exogenous insulin, normal blood glucose concentration, normal or nearnormal $\mathrm{HbAlc}$, and prompt correction of ketoacidosis. The response to oral and intravenous glucose challenge and to secretagogues such as arginine are re-established. ${ }^{29}$ Because of improved glucagon and epinephrine responses, glucose-counter-regulation after hypoglycaemia is also restored. ${ }^{30,31}$ This has a profound impact on the quality of life since after successful transplantation hypoglycaemic unawareness is unlikely to occur. ${ }^{32}$ The majority of subjects undergoing successful transplantation consider management of the 
immunosuppressive therapy preferable to insulin injections or other metabolic complications of the disease. ${ }^{33}$

Amelioration of diabetes-associated morbidity-Numerous studies have shown that a successful pancreas transplant can slow micro-vascular complications, including nephropathy, retinopathy and neuropathy. ${ }^{34-37}$ Disappointingly, however, clear evidence has not emerged showing that pancreas transplantation can reverse pre-existing lesions or completely prevent the progression of new ones that are diabetes-related. This could be the result of factors that are independent of glycaemic control. Such questions about the full nature of the disease are being investigated in detail, including in long-term epidemiological studies of diabetic versus non-diabetic populations.

\section{The worldwide experience}

More than 15000 pancreas transplants have been reported to the International Pancreas Transplantation Registry (IPTR). ${ }^{38}$ The actual number of cases is undoubtedly higher because not all centres report to this registry. The transplants contributed year by year from 1978 to 2000 are shown in Figure 4. More than $80 \%$ of the allografts were co-transplanted with a kidney, but there have been more solitary pancreases in recent years. Patient survival reported by IPTR at 1 year is $>90 \%$ with simultaneous kidney-pancreas, pancreas after kidney and pancreas alone transplantation. However, graft survival (insulin-free status) has been lower with solitary pancreas (71\%) than with simultaneous kidney-pancreas transplantation (84\%). Although no survival difference was reported with bladder versus enteric drainage of exocrine secretion, there has been increasing use of enteric drainage.

While such registry data are valuable, a better understanding of how pancreas transplantation evolved into a genuine clinical service is obtained from detailed reports from large experienced centres. ${ }^{25,39-45}$ At present, only a half dozen surviving recipients are known to have borne functioning pancreas allografts that were transplanted before 1985 and none before $1976 .{ }^{46}$ Early deaths and graft losses from technical complications, infections and rejection reached an acceptably low level only since 1995, due largely to the widespread acceptance of tacrolimus in that year. However, late deaths continue from cardiac, infectious and peripheral vascular disease, and from de novo malignancies. Most of these complications can be traced to, or are aggravated by, the need for chronic immunosuppression. As described below, it may be possible to rectify this problem at least partly.

\section{Mechanisms of engraftment}

In the different eras, the successful reversal of rejection was followed by a decline in antidonor graft reactivity that was reflected by a reduced need for immunosuppression, and in some cases by eventual or complete independence from maintenance therapy. ${ }^{47-49}$ Even when rejection is not clinically evident, the need for immunosuppression declines. The implication was that an allograft transplanted under non-specific immunosuppression could induce variable degrees of antigen-specific non-reactivity (tolerance). ${ }^{50}$

In each era, however, a policy drift ensued as soon as it was recognized that some of the rejections developing under monotherapy were intractable. The management change consisted of instituting prophylactic high-dose steroid therapy from the time of transplantation to all recipients. As antilymphoid and other agents were added pre-emptively in increasingly complex cocktails, the unchallenged tacit assumption was that the efficacy of the immunosuppressive regimens could be assessed primarily by the frequency with which acute rejection could be prevented. In addition, it was assumed that reducing the incidence of early rejection to near zero would be rewarded by a commensurate decline in chronic 
rejection. Instead, chronic rejection has become the greatest unresolved problem in the transplantation of all organs, with the possible exception of the liver.

Relinquishing the use of high-dose immunosuppression was difficult to defend, largely because the mechanisms of alloengraftment were enigmatic. The first real clue to these mechanisms was the discovery in 1992 that bone-marrow-derived passenger leukocytes, which are normal constituents of all organs, migrated after transplantation to widespread locations in the recipient and could be found peripherally in small numbers, years or decades later. ${ }^{51-53}$ With only this much information, it was deduced that the early events after transplantation are dominated by homing of multilineage donor leukocytes from the organ graft to the recipient lymphoid tissues where the immune competent donor and recipient leukocyte populations underwent reciprocal clonal activation (i.e. host-versus-graft (HVG) and graft-versus-host (GVH) reactions) (Figure 5).

For organ engraftment, the two immune responses must be succeeded by a significant degree of reciprocal clonal exhaustion-deletion (Figure 5). The long-term maintenance of this acutely-achieved state of variable deletional tolerance depends on persistence of the donor leukocytes (micro- or macrochimerism) whose survival is aided by a second mechanism of immune indifference. ${ }^{54,55}$ Both mechanisms of antigen-specific nonreactivity (clonal exhaustion-deletion and immune ignorance) are regulated by migration and localization of the only mobile antigen of the organ, namely, the donor leukocytes. ${ }^{54,55}$

Such organ-induced tolerance has been well documented in the absence of immunosuppression in a limited number of mouse, rat and pig models, most frequently involving, but not limited to, transplantation of the leukocyte rich liver (summarized in ref. 47). In most models, however, and clinically, an umbrella of immunosuppression is required. Otherwise, one immunocyte population destroys the other before the tolerogenic events can occur (Figure 5). The usual outcome is organ rejection, but graft-versus-host disease (GVHD) may be the dominant pathophysiology in a number of experimental models and clinically. The outcomes of rejection or GVHD can be forestalled or permanently prevented in many animal models by treating the organ recipient after transplantation with a short course of a wide variety of immunosuppressive drugs, or sometimes with a single dose.

Comparably conducive conditions for tolerance after human organ transplantation are predictably present only when tissues and organs are transplanted from HLA identical sibling donors. In addition, the short-term immunosuppression used in experimental organ transplant models is contrary to the policy of heavy early immunosuppression (so-called 'induction therapy'), and to the commitment made at the outset to lifetime therapy. The early loss of allografts from immunological causes has been all but eliminated by intense immunosuppression, but not chronic rejection.

Because immune activation and subsequent clonal exhaustion-deletion is the seminal mechanism by which variable organ-induced non-reactivity is achieved ${ }^{51-55}$, the obvious question is whether conventional heavy immunosuppression early after transplantation erodes the window of opportunity for tolerogenesis that is opened with immune activation a few hours after graft revascularization reaches a zenith in 1-3 weeks, and is largely closed by 1 or 2 months (Figure 5). We have addressed this issue recently, and have proposed two key therapeutic principles that must be observed if low-dose or no-dose immunosuppression is to be achieved in pancreas and other kinds of organ recipients.

The first treatment principle, exemplified by conventional bone marrow transplantation to cytoablated (e.g. irradiated) recipients, is that host pre-treatment facilitates alloengraftment. Near total chimerism with antigen-specific tolerance can be regularly established with clinical bone marrow transplantation to the cytoablated recipient, using minimal post- 
transplant immunosuppression. The reason is that, with host cytoablation before arrival of the mobile donor leukocytes, the donor-specific clonal expansion of the bone marrow recipient response is small enough to be acutely deleted by the infused donor haematopoietic cells before these donor cells are rejected. Although this has been accomplished clinically under the well standardized circumstances of conventional bone marrow transplantation, the widespread use of combined bone marrow-organ transplantation to cytoablated recipients has been precluded by the many parameters involved, of which the most restrictive is the need for a histocompatible donor for avoidance of GVHD.

The second key therapeutic principle is the avoidance of excessive and/or inappropriately timed (and therefore antitolerogenic) immunosuppression. The strong prophylactic immunosuppression conventionally used to inhibit the donor-specific T-cell response and avert rejection of the graft passenger leukocytes coincidentally limits the extent of exhaustion-deletion and tolerogenesis, as has been demonstrated experimentally with prednisone, cyclosporine, tacrolimus and other agents.

Variable violations of both therapeutic principles are inevitable with compromise strategies between the radically different regimens of conventional bone marrow and organ transplantation. However, scrupulous adherence to the first principle of recipient pretreatment, but using non-myelotoxic agents for conditioning (e.g. antilymphoid antibody preparations), and observance of the second principle of minimal post-transplant immunosuppression, should improve clinical results. In addition, because the graft passenger leukocytes constitute, in essence, the equivalent of a bone marrow infusion, it is rational to expect that the infusion of adjunct donor bone marrow cells will facilitate the clonal deletion induced by the comparable graft migratory leukocytes. In the past ${ }^{56-58}$ this desired effect of adjunct donor bone marrow probably has been subverted by over-immunosuppression. ${ }^{55}$

Either without, or more likely with, adjunct donor bone marrow infusion, it may be possible to achieve drug-free tolerance in recipients of pancreas or other organs, using a clinical protocol that was developed in 1966 after demonstrating that ALG had a more tolerogenic effect when it was given before, rather than after, kidney and liver transplantation in dogs. ${ }^{18}$ Under similar management in humans, but armed with modern drugs including powerful antilymphoid antibody agents, a markedly reduced need for early and maintenance immunosuppression (including nearly complete elimination of prednisone) has been reported from several centres. In Cambridge (England), Calne et al ${ }^{58}$ have treated cadaver kidney recipients with a few perioperative doses of a humanized depleting anti-CD52 monoclonal antibody ( $\mathrm{T}$ and $\mathrm{B}$ cell plus monocyte reactive), followed by low maintenance doses of cyclosporine alone. The results have been duplicated by Allen Kirk and associates in Bethesda by combining the antibody treatment with maintenance rapamycin. ${ }^{59}$ Further suggesting that the therapy is not immunosuppressant-specific, but depends on the dose and timing of therapy, Kirk obtained similar results using a potent polyclonal ALG $\left(\right.$ Thymoglobulin $^{\mathrm{R}}$ ) and low-dose rapamycin. ${ }^{59}$

\section{A potential era 4}

The two therapeutic principles of recipient pre-treatment and minimal post-transplant immunosuppression were applied in Pittsburgh between July and November 2001 for four adult recipients of pancreas-only cadaveric allografts and for 10 kidney-pancreas recipients. Ten of the patients were also infused perioperatively with $5-9 \times 10^{8}$ unmodified bone marrow cells from the same donor. The patients were preconditioned with $3-5 \mathrm{mg} / \mathrm{kg}$ Thymoglobulin ${ }^{R}$ under the cover of $1 \mathrm{~g}$ intravenous methopredniso-lone as prophylaxis against cytokine reactions. Treatment post-transplantation was with tacrolimus only with a trough target level of $10 \mathrm{ng} / \mathrm{ml}$ unless clinically significant rejection prompted the addition of a prednisone bolus(s), maintenance prednisone, or a short course of sirolimus. 
All 14 of the pancreases and the 10 co-transplanted kidneys have functioned well with follow-ups that are now 2 weeks to 6 months. The absence, or easy control, of both early and late rejection in this consecutive cadaveric series, using minimum immunosuppression relative to all previous experience in pancreas transplantation, has been remarkable. The value of this approach has been supported by similar results in a contemporaneous series of 31 recipients of cadaveric kidneys who had even less need for immunosuppression other than tacrolimus monotherapy. An attempt at complete weaning of immunosuppression is planned for patients under monotherapy whose allograft biopsy(ies) at 100 days shows no evidence of destructive immunity. Patients who have donor leukocyte chimerism demonstrable by flow cytometry in blood samples (i.e. macrochimerism) will be considered particularly good candidates for weaning.

\section{PANCREATIC ISLET TRANSPLANTATION}

The concept of removing islets from the whole pancreas for separate engraftment was advanced as early as $1902 .{ }^{60}$ Eighty years later it was demonstrated in animal models ${ }^{61,62}$ and clinically ${ }^{63}$ that a high rate of success with islet transplantation can be expected in the absence of an immune barrier (i.e. using autografts). In most of the autotransplant trials, the pancreas was removed surgically (e.g. for pancreatitis), purified islets were extracted from the specimen, and these were infused into the patient's liver via the portal vein. Efforts to duplicate such results with allograft islets were not rewarded with success in experimental animals until the 1980s, or in humans until 1990.

In the first successful transplantation of islet allografts, five patients in Pittsburgh underwent upper abdominal exenteration (which included removal of the liver, stomach and whole pancreas), followed by liver transplantation. ${ }^{64}$ The patients were rendered free of exogenous insulin for up to 5 years by intraportal infusion of pancreatic islet allografts that had been prepared from the pancreas of the liver donor. However, when the same investigators attempted islet transplantation in nearly three dozen patients with juvenile diabetes, complete long-term insulin independence was not achieved in any case.

Subsequently, several groups have documented metabolic normalization after the transplantation of islet allografts in patients with type 1 diabetes. Some 237 such attempts were reported to the International Islet Transplant Registry (IITR) between 1990 and 1999, with insulin independence at 1 year in about $10 \% .{ }^{65}$ Most recently, Shapiro et al reported successful metabolic correction in seven consecutive type 1 recipients of islets, most commonly requiring islets from more than one donor. ${ }^{66}$ Immunosuppression was provided initially with an anti-interleukin-2 receptor antagonist (daclizumab). Continuous posttransplant treatment was with a steroid-free drug combination based on tacrolimus. Efforts to duplicate these results in several European and American centres have confirmed the feasibility of the islet procedure, but not its reliability.

Consequently, in addition to pursuing these trials in multiple centres, efforts are being made to determine the precise conditions that lead to more consistently successful engraftment:

1. Isolation of islets. This first step involves enzymatic digestion of the pancreas ${ }^{67}$, achieved by intraductal injection of a solution containing collagenase or a recently improved blend of enzymes (Liberase ${ }^{\mathrm{R}}$ ). The digestion is combined with mechanical disruption in a semi-automated digestion chamber developed by Ricordi et al. ${ }^{68}$ After separation of the islets and discard of the acinar cells, islet clusters remain of variable size, each ranging from 50 to $500 \mu \mathrm{m}$ in diameter. The implantable pellet of islets has a compacted volume of only 1-3 $\mathrm{ml}$. It has been estimated that approximately $50 \%$ of the original islet mass has already been lost by this stage. Ways of obtaining a better yield are being sought. 
2. Characterization of the islets. Many studies have focused on the effect of different culture media and supplements that would allow preservation of islet mass. In addition to making islet transplantation an elective procedure, this would allow time to assess in vitro the function and other qualities of the potential grafts. 69,70 Cryopreservation also has been shown to be feasible ${ }^{71,72}$, but these methods at present entail a further significant loss of islets.

3. Genetic modification. Isolated islets can be altered to acquire resistance to toxic and other factors chat cause $\beta$-cell damage, but the clinical value of these methods has not been established. ${ }^{72-75}$

4. Differentiation of precursor cells into insulin producing tissues. This promising research has demonstrated the feasibility of directing undifferentiating pancreatic and extra-pancreatic tissue toward a $\beta$-cell phenotype, including insulin secretion. ${ }^{76-78}$

5. Implantation site. Once isolated from their physiological and anatomical environment, islet cells rapidly undergo metabolic failure, necrosis and eventually apoptosis. ${ }^{79,80}$ The influence of the various implantation sites on these adverse events, including the immune response elicited, is not known. Intestinal mucosa, thymus, spleen, kidney capsule, peritoneum, testicle, subcutaneous tissue, liver and intra-cerebral space have been evaluated. ${ }^{81-86}$ The most common implantation site in clinical trials has been within the liver via intra-portal injection. ${ }^{70-87}$ Whether the liver is the optimal place for engraftment has not been proved.

6. Glucose counter-regulation. In contrast to whole-organ transplantation, the glucagon response to hypoglycaemia and other counter-regulatory mechanisms in recipients of well-functioning islet grafts appears to be impaired ${ }^{88,89}$; this may be related to the implantation site.

\section{Immunosuppression and alloengraftment}

As described under Pancreas Transplantation, the engraftment of all whole organs, including the pancreas, begins with acute chimerism-dependent induction of some level of deletional tolerance. The subsequent maintenance of the clonal exhaustion requires the persistence of small numbers of donor leukocytes (microchimerism) whose survival is facilitated by migration of donor leukocytes to 'protected' non-lymphoid areas where the donor cells may be 'ignored' by the host immune system until they leak back to host lymphoid organs and perpetuate clonal exhaustion-deletion. ${ }^{54,55}$ In such cases, immune ignorance of the cells in non-lymphoid locations is a secondary (or collaborative) mechanism for maintenance of clonal deletion, as described in detail elsewhere. ${ }^{54,55}$

In contrast to whole organs, small bits of endocrine tissue that fail to reach organized lymphoid collections may be unrecognized by the host immune system. In an early example of such immune ignorance, Stone, Owings and Gey ${ }^{90}$ reported in 1934 that parathyroid tissue, which had been cultured for 2 weeks and transplanted into loose areolar subcutaneous tissue, functioned for prolonged periods in canine and human recipients. Long regarded as not credible, the findings of these authors are explained in retrospect by two features of the procedure. The first was the choice of a subcutaneous implantation site, which, like other privileged sites (e.g. hamster cheek pouch, brain), has limited lymphatic drainage. The second feature of this procedure became apparent with Lafferty's demonstration that tissue culture comparable to that used four decades earlier in the parathyroid experiments of Stone et al depletes endocrine tissue of passenger leukocytes that are capable of migrating to host lymphoid organs. ${ }^{91}$ 
In principle, the use of highly bio-compatible materials used to encapsulate islet cells is an attempt to achieve immune indifference with a mechanical barrier. ${ }^{92,93}$ However, because islets have insufficient donor leukocyte antigen to induce deletion, it is possible that the islet engraftment may be achieved primarily by immune ignorance without encapsulation, resembling the 'Stone-Lafferty' graft. This could occur if the small numbers of mobile donor leukocytes contained in a bolus of islets made their way to host lymphoid organs and were 'all' destroyed, allowing the leukocyte-depleted islets in distant non-lymphoid locations to be ignored by the host for long periods, or permanently. From practical experience, and particularly that of the Edmonton group, it would appear that the immunosuppression most conducive for this chain of events may be the same as that for whole-organ transplantation: i.e. recipient pre-treatment and minimal steroid-free posttransplant therapy.

\section{XENOTRANSPLANTATION}

The prospect of providing either a whole pancreas or islets for the large number of diabetic patients that could benefit from transplantation is limited by the shortage of donors. At present more than one islet donor is required to accomplish glucose normalization and longterm maintenance may require further cell infusions. The solution may be the use of animal donors. ${ }^{94}$ Because human and porcine insulin have high amino acid sequence homology and have other metabolic similarities, including glucose homeostasis and regulation of insulin secretion, the pig may be a suitable source for islet cells or for the whole pancreas. A pilot study performed in Sweden has shown that fetal porcine islets can be implanted in humans, but these xenografts have had short functional activity because of rejection by predominantly innate immune mechanisms. ${ }^{95}$

The best characterized target antigen on the cells of lower mammals (e.g. pig) is the surface carbohydrate epitope galactose $\alpha(1-3)$ galactose, which is similar to substances found on numerous bacteria, protozoa and viruses. Efforts to create transgenic pigs that have this and other suspect genes replaced or knocked-out are underway. ${ }^{96,97}$ Combined with cloning technology, they may allow the creation of 'humanized' animals for clinical use.

Practice points

- besides insulin, a definitive treatment for type 1 diabetes can be achieved only with whole-pancreas or islet-cell transplantation

- long-term normalization of glycaemia is achieved by whole-pancreas transplants, limited by technical complications of the extensive surgery

- islet transplantation is non-invasive; it is limited in its use by the need for multiple donors

- immunosuppressive regimens are necessary in both types of transplant to limit the negative effects of recurrent autoimmunity and allorejection

- immunosuppressants allow successful transplants in adults, but not in children

Research agenda

- tolerization protocols need to be implemented. Immunological preconditioning by anti-T cell antibodies (e.g. Tymoglobulin) and donor bone marrow administration could represent a possible approach for the induction of haematological chimerism of the recipient 
- alternative sources of insulin-producing ( $\beta$ cells can be found among the stem cells present in the individual's tissues (e.g. endocrine pancreas, bone marrow, liver). These precursors should be immunologically recognized and then induced to proliferate and differentiate

- the limit in organ availability can also be overcome by generating animal donors (e.g. Pigs) with tissues immunologically more acceptable by the human recipient, allowing xenotransplantation

\section{REFERENCES}

1. Report of a WHO Consultation. Geneva: World Health Organization; 1999. Definition, diagnosis and classification of diabetes mellitus and its complications.

2. Amos AF, McCarthy DJ, Zimmet P. The rising global burden of diabetes and its complications: estimates and projections to the year 2010. Diabetes Medicine. 1997; 14 supplement 5:S1-S85.

3. Harris MI. Diabetes in America: epidemiology and scope of the problem. Diabetes Care. 1998; 21 supplement 3:C11-C14. [PubMed: 9850480]

4. Bjork S. The cost of diabetes and diabetes care. Diabetes Research and Clinical Practice. 2001; 54 supplement 1:S13-S18. [PubMed: 11580964]

5. American Diabetes Association. Diabetic Nephropathy. Diabetes Care. 1998; 21(1S):5OS-53S.

6. Gu K, Cowie CC, Harris MI. Mortality in adults with and without diabetes in a national cohort of the U.S. population, 1971-1993. Diabetes Care. 1998; 21:1138-1145. [PubMed: 9653609]

7. American Diabetes Association. Diabetic Retinopathy. Diabetes Care. 1998; 21(1S):47S-49S.

8. The Diabetes Control and Complications Trial Research Group. Effect of intensive therapy on residual beta-cell function in patients with type 1 diabetes in the Diabetes Control and Complications Trial: A Randomized, Controlled Trial. Annals of Internal Medicine. 1998; 128:517523. [PubMed: 9518395]

9. Petruzzo P, Andreelli F, McGregor B, et al. Evidence of recurrent type 1 diabetes following HLAmismatched pancreas transplantation. Diabetes Metabolism. 2000; 26:215-218. [PubMed: 10880896]

10. Gibson T, Medawar PB. The fate of skin homografts in man. journal of Anatomy. 1943; 77:299310. [PubMed: 17104936]

11. Starzl TE. History of clinical transplantation. World Journal of Surgery. 2000; 24:759-782. [PubMed: 10833242]

12. Murray JE, Merrill JP, Harrison JH, et al. Prolonged survival of human-kidney homografts by immunosuppressive drug therapy. New England Journal of Medicine. 1963; 268:1315-1323. [PubMed: 13936775]

13. Calne RY, Rolles K, White DJG, et al. Cyclosporin A initially as the only immunosuppressant in 34 recipients of cadaveric organs, 32 kidneys, 2 pancreases, and 2 livers. Lancet. 1979; 2:10331036. [PubMed: 91781]

14. Starzl TE, Todo S, Fung J, et al. FK 506 for human liver, kidney and pancreas transplantation. Lancet. 1989; ii:1000-1004. [PubMed: 2478846]

15. Groth CG, Backman L, Morales JM, et al. Sirolimus (rapamycin)-based therapy in human renal transplantation: similar efficacy and different toxicity compared with cyclosporine. Sirolimus European Renal Transplant Study Group. Transplantation. 1999; 67:1036-1042. [PubMed: 10221490]

16. Sollinger HW. For the U.S. Renal Transplant Mycophenolate Mofetil Study Group. Mycophenolate mofetil for the prevention of acute rejection in primary cadaveric renal allograft recipients. Transplantotion. 1995; 60:225-232.

17. Starzl TE, Marchioro TL, Waddell WR. The reversal of rejection in human renal homografts with subsequent development of homograft tolerance. Surgery, Gynecology, and Obstetrics. 1963; 117:385-395. 
18. Starzl TE, Marchioro TL, Porter KA, et al. The use of heterologous antilymphoid agents in canine renal and liver homotransplantation and in human renal homotransplantation. Surgery, Gynecology, and Obstetrics. 1967; 124:301-318.

19. Lillehei RC, Simmons RL, Najarian JS, et al. Pancreaticoduodenal allotransplantation: Experimental and clinical observations. Annals of Surgery. 1970; 172:405-436. [PubMed: 4918002]

20. Brekke, IB. Experimental background. In: Groth, CG., editor. Pancreatic Transplantation. Philadelphia, PA: WB Saunders Company; 1988. p. 21-35.

21. Kelly WD, Lillehei RC, Merkel FK. Allotransplantation of the pancreas and duodenum along with the kidney in diabetic nephropathy. Surgery. 1967; 61:827-835. [PubMed: 5338113]

22. Gliedman ML, Gold M, Whittaker J, et al. Clinical segmental pancreatic transplantation with ureter-pancreatic duct anastomosis for exocrine drainage. Surgery. 1973; 74:171-180. [PubMed: 4577803]

23. Nghiem DD, Gonwa TA, Corry RJ. Metabolic affects of urinary diversion of exocrine secretions in pancreas transplantation. Transplantation. 1987; 43:70-73. [PubMed: 3541327]

24. Sollinger HW, Kalayoglu M, Hoffman RM, et al. Quadruple immunosuppressive therapy in whole pancreas transplantation. Transplantation Proceedings. 1987; 19:2297-2299. [PubMed: 3274511]

25. Sollinger HW, Odorico JS, Knechtle SJ, et al. Experience with 500 simultaneous pancreas-kidney transplants. Annals of Surgery. 1998; 228:284-296. [PubMed: 9742912]

26. Starzl TE, Porter KA, Francavilla A. The Eck fistula in animals and humans. Current Problems in Surgery. 1983; 20:687-752. [PubMed: 6357642]

27. Diem P, Abid M, Redmon JB, et al. Systemic venous drainage of pancreas allografts as independent cause of hyperinsulinemia in type 1 diabetic recipients. Diabetes. 1990; 39:534-540. [PubMed: 2185105]

28. Stratta R, Shokouh-Amiri MH, Egidi MF, et al. A prospective comparison of simultaneous kidney pancreas transplantation with systemic-enteric versus portal-enteric drainage. Annals of Surgery. 2001; 233:740-751. [PubMed: 11371732]

29. Robertson RP. Seminars in medicine of the Beth Israel Hospital, Boston: pancreatic and islet transplantation for diabetes - cures or curiosities? New England journal of Medicine. 1992; 327:1861-1868. [PubMed: 1448124]

30. Diem P, Redmon JB, Abid M, et al. Glucagon, catecholamine and pancreatic polypeptide secretion in type 1 diabetic recipients of pancreas allografts. Journal of Clinical Investigation. 1990; 86:2008-2013. [PubMed: 2254456]

31. Barrou Z, Seaquist ER, Robertson RP. Pancreas transplantation in diabetic humans normalizes hepatic glucose production during hypoglycemia. Diabetes. 1994; 43:661-666. [PubMed: 8168643]

32. Kendall DM, Rooney DP, Smets YF, et al. Pancreas transplantation restores epinephrine response and symptom recognition during hypoglycemia in patients with long-standing type 1 diabetes and autonomic neuropathy. Diabetes. 1997; 46:249-257. [PubMed: 9000702]

33. Piehlmeier W, Bullinger M, Nusser J, et al. Quality of life in type 1 (insulin-dependent) diabetic patients prior to and after pancreas and kidney transplantation in relation to organ function. Diabetologia. 1991; 34 supplement 1:S150-S157. [PubMed: 1936684]

34. Cheung AT, Perez RV, Chen PC. Improvements in diabetic microangiopathy after successful simultaneous pancreas-kidney transplantation: a computer-assisted intravital microscopy study on the conjunctival microcirculation. Transplantation. 1999; 68:927-932. [PubMed: 10532529]

35. Chow VC, Pai RP, Chapman JR, et al. Diabetic retinopathy after combined kidney-pancreas transplantation. Clinical Transplantation. 1999; 13:356-362. [PubMed: 10485379]

36. Allen RD, Al-Harbi IS, Morris JG, et al. Diabetic neuropathy after pancreas transplantation: determinants of recovery. Transplantation. 1997; 63:830-838. [PubMed: 9089222]

37. Solders G, Tyden G, Persson A, Groth CG. Improvement of nerve conduction in diabetic neuropathy. A follow-up study $4 \mathrm{yr}$ after combined pancreatic and renal transplantation. Diabetes. 1992; 41:946-951. [PubMed: 1628768]

38. International Pancreas Transplant Registry. Newsletter. 2001; 13(1) 
39. Sutherland DE, Gruessner RW, Dunn DL, et al. Lessons learned from more than 1,000 pancreas transplants at a single institution. Annals of Surgery. 2001; 233:463-501. [PubMed: 11303130]

40. Corry RJ, Chakrabarti PK, Shapiro R, et al. Simultaneous administration of adjuvant donor bone marrow in pancreas transplant recipients. Annals of Surgery. 1999; 230:372-379. [PubMed: 10493484]

41. Stratta RJ, Gaber AO, Shokouh-Amiri MH, et al. Evolution in pancreas transplantation techniques; simultaneous kidney-pancreas transplantation using portal-enteric drainage without antilymphocyte induction. Annals of Surgery. 2000; 229:701-708. [PubMed: 10235529]

42. Tyden G, Bolinder J, Solders G, et al. Improved survival in patients with insulin-dependent diabetes mellitus and end-stage diabetic nephropathy 10 years after combined pancreas and kidney transplantation. Transplantation. 1999; 67:645-648. [PubMed: 10096516]

43. Henry ML, Elkhammas EA, Bumgardner GL, et al. Outcome of 300 consecutive pancreas-kidney transplants. Transplantation Proceedings. 1998; 30:291. [PubMed: 9532045]

44. Bartlett ST, Schweitzer EJ, Johnson LB, et al. Equivalent success of simultaneous pancreas kidney and solitary pancreas transplantation. A prospective trial of tacrolimus immunosuppression with percutaneous biopsy. Annals of Surgery. 1996; 224:440-449. [PubMed: 8857849]

45. DiLandro D, Koenigsrainer A, Oefiner D, et al. Experience with 100 combined pancreatic renal transplantations in a single center. Nephron. 1996; 72:547-551. [PubMed: 8730419]

46. Terasaki, PI. The HLA-matching effect in different cohorts of kidney transplant recipients. In: Terasaki, PI.; Cecka, JM., editors. Clinical Transplants 2000. Los Angeles: UCLA Immunogenetics Center; 2001. p. 529-531.

47. Starzl TE, Demetris AJ, Murase N, et al. The lost chord: microchimerism. Immunology Today. 1996; 17:577-584. 588. [PubMed: 8991290]

48. Ramos HC, Reye J, Abu-Elmagd K, et al. Weaning of immunosuppression in long term liver transplant recipients. Transplantation. 1995; 59:212-217. [PubMed: 7839442]

49. Mazariegos GV, Reyes J, Marino I, et al. Weaning of immunosuppression in liver transplant recipients. Transplantation. 1997; 63:243-249. [PubMed: 9020325]

50. Starzl, TE. Experience in Hepatic Transplantation. Philadelphia: WB Saunders Company; 1969. p. 229-232.

51. Starzl TE, Demetris AJ, Murase N, et al. Cell migration, chimerism, and graft acceptance. Lancet. 1992; 339:1579-1582. [PubMed: 1351558]

52. Starzl TE, Demetris AJ, Trucco M, et al. Systemic chimerism in human female recipients of male livers. Lancet. 1992; 340:876-877. [PubMed: 1357298]

53. Starzl TE, Demetris AJ, Trucco M, et al. Cell migration and chimerism after whole organ transplantation: the basis of graft acceptance. Hepatology. 1993; 17:1127-1152. [PubMed: 8514264]

54. Starzl TE, Zinkernagel RM. Antigen localization and migration in immunity and tolerance. New England journal of Medicine. 1998; 339:1905-1913. [PubMed: 9862947]

55. Starzi TE, Zinkernagel RM. Regulation of transplant rejection, engraftment, and tolerance by antigen migration and localization: an historical perspective. Nature Reviews in immunology. 2001; 1:233-239.

56. Barbei WH, Mankin JA, Laskow D, et al. Long term results of a controlled prospective study with transfusion of donor-specific bone marrow in 57 cadaveric renal allograft recipients. Transplantation. 1991; 51:70-75. [PubMed: 1987708]

57. Fontes P, Rao A, Demetris AJ, et al. Augmentation with bone marrow of donor leukocyte migration for kidney, liver, heart, and pancreas islet transplantation. Lancet. 1994; 344:151-155. [PubMed: 7912764]

58. Caine R, Moffart SD, Friend PJ. Campath iH allows low-dose cyclosporine monotherapy in 31 cadaveric renal allograft recipients. Transplantation. 1999; 68:1613-1616. [PubMed: 10589966]

59. Kirk AD, Swanson SJ, Mannon RB, et al. Preliminary results from a human tolerance trial using campath-IH (abstract), or rabbit polyclonal antithymocyte globulin (abstract). American Journal of Transplantation. 2001; 1:136-137. [PubMed: 12108436]

60. Ssoboiew LW. Zur normalen und pathologische morphologie der inneren secretion der bauchspeichei-druse. Virchows Archives of Pathologic Anatomy. 1902; 168:91-128. 
61. Pipeleers-Marichal MA, Pipeleers DG, Cutler PE, et al. Metabolic and morphologic studies in intraportal-islet-transplanted rats. Diabetes. 1976; 25:1041-1051. [PubMed: 136376]

62. Grey DWR, Warnock GL, Sutton R, et al. Successful autotransplantation of isolated islets of Langerhans in the cynomolgus monkey. British Journal of Surgery. 1986; 73:850-853. [PubMed: 3094618]

63. Najarian JS, Sutherland DER, Baumgartner D, et al. Total or near total pancreatectomy and islet autotransplantation for treatment of chronic pancreatitis. Annals of Surgery. 1980; 192:526-542. [PubMed: 6775603]

64. Tzakis AG, Ricordi C, Alejandro R, et al. Pancreatic islet transplantation after upper abdominal exenteration and liver replacement. Lancet. 1990; 336:402-405. [PubMed: 1974944]

65. International Islet Transplant Registry. Newsletter 9. 2001; vol 8

66. Shapiro AMJ, Lakey JRT, Ryan EA. Islet transplantation in seven patients with type 1 diabetes mellitus using a glucocorticoid-free immunosuppressive regimen. New England Journal of Medicine. 2000; 343:230-238. [PubMed: 10911004]

67. Lacy PE, Kostianovsky M. Method for the isolation of intact islets of Langerhans from the rat pancreas. Diabetes. 1967; 16:35-39. [PubMed: 5333500]

68. Ricordi C, Lacy PE, Finke EH, et al. Automated method for isolation of human pancreatic islets. Diabetes. 1988; 37:413-420. [PubMed: 3288530]

69. London NJ, Swift SM, Clayton HA. Isolation, culture and functional evaluation of islets of Langerhans. Diabetes Metabolism. 1998; 24:200-207. [PubMed: 9690051]

70. Keymeulen B, Ling Z, Gorus FK, et al. Implantation of standardized beta-cell grafts in a liver segment of IDDM patients: graft and recipient characteristics in two cases of insulin-independence under maintenance immunosuppression for prior kidney grafts. Diabetologia. 1998; 41:452-459. [PubMed: 9562350]

71. Rajotte RV. Islet cryopreservation protocols. Annals of the New York Academy of Sciences. 1999; 875:200-207. [PubMed: 10415568]

72. Lakey JR, Warnock GL, Ao Z, et al. Bulk cryopreservation of isolated islets of Langerhans. Cell Transplantation. 1996; 5:395-404. [PubMed: 8727008]

73. Giannoukakis N, Rudert WA, Robbins PD, Trucco M. Targeting autoimmune diabetes with gene therapy. Diabetes. 1999; 48:2107-2121. [PubMed: 10535443]

74. Giannoukakis N, Rudert WA, Trucco M, Robbins PD. Protection of human islets from the effects of interleukin-lb by adenoviral gene transfer of an 1 repressor. Journal of Biological Chemistry. 2000; 275:36509-36513. [PubMed: 10967112]

75. Alexander A, Crawford M, Bertera S, et al. Indoleamine 2,3-dioxygenase expression in transplanted NOD islets prolongs graft survival after adoptive transfer of diabetogenic splenocytes. Diofaetes. 2002; 51:356-365.

76. Soria B, Roche E, Berna' G, et al. Insulin-secreting cells derived from embryonic stem cells normalize glycemia in streptozotocin-induced diabetic mice. Diabetes. 2000; 49:157-162. [PubMed: 10868930]

77. Ramiya VK, Maraist M, Arfors KE, et al. Reversal of insulin-dependent diabetes using islets generated in vitro from pancreatic stem cells. Nature Medicine. 2000; 6:278-282.

78. Bonner-Weir S, Taneja M, Weir GC, et al. In vitro cultivation of human islets from expanded ductal tissue. Proceedings of the National Academy of Sciences of the USA. 2000; 97:7999-8004. [PubMed: 10884429]

79. Paraskevas S, Maysinger D, Wang R, et al. Cell loss in isolated human islets occurs by apoptosis. Pancreas. 2000; 20:270-276. [PubMed: 10766453]

80. Ilieva A, Yuan S, Agapitos D, et al. Pancreatic islet cell survival following islet isolation: the role of cellular interactions in the pancreas. Journal of Endocrinology. 1999; 161:357-364. [PubMed: 10333538]

81. Posselt AM, Barker CF, Tomaszewski JE, et al. Induction of donor-specific unresponsiveness by intrathymic islet transplantation. Science. 1990; 249:1293-1295. [PubMed: 2119056]

82. Kemp CB, Knight MJ, Scharp DW, et al. Transplantation of isolated pancreatic islets into the portal vein of diabetic rats (letter). Nature. 1973; 244:447. [PubMed: 4200461] 
83. Hayek A, Beattie GM. Intrapancreatic islet transplantation in experimental diabetes in the rat. Metabolism. 1992; 41:1367-1369. [PubMed: 1461143]

84. Cameron DF, Whittington K, Schultz RE, et al. Successful islet/abdominal testis transplantation does not require Leydig cells. Transplantation. 1990; 50:649-653. [PubMed: 2171164]

85. Tchervenivanov N, Metrakos P, Kokugawa Y, et al. Submucosal transplantation of pancreatic islets. Transplantation Proceedings. 1994; 26:680-681. [PubMed: 8171608]

86. Yasunami Y, Lacy PE, Finke EH. A new site for islet transplantation - a peritoneal-omental pouch. Transplantation. 1983; 36:181-182. [PubMed: 6410557]

87. Mintz, DH.; Alejandro, R.; Miller, J. Human islet transplantation: the University of Miami experience. In: van Schilfgaarde, R.; Hardy, MA., editors. Transplantation of the Endocrine Pancreas in Diabetes Mellitus. Amsterdam: Elsevier; 1988. p. 234-239.

88. Kendall DM, Teuscher AU, Robertson RP. Defective glucagon secretion during sustained hypoglycemia following successful islet allo- and autotransplantation in humans. Diabetes. 1997; 46:23-27. [PubMed: 8971076]

89. Gupta V, Wahoff DC, Rooney DP, et al. The defective glucagon response from transplanted intrahepatic pancreatic islets during hypoglycemia is transplantation site-determined. Diabetes. 1997; 46:28-33. [PubMed: 8971077]

90. Stone HB, Owings JC, Gey GO. Transplantation of living grafts of thyroid and parathyroid glands. Annals of Surgery. 1934; 100:613-628. [PubMed: 17856382]

91. Lafferty KJ, Prowse SJ, Simeonovic CJ. Immunobiology of tissue transplantation: a return to the passenger leukocyte concept. Annual Review of Immunology. 1983; 1:143-173.

92. Prevost PH, Flori S, Collier C, et al. Application of AN69 Hydrogel to islet encapsulation. Annals of the New York Academy of Sciences. 1997; 831:344-349. [PubMed: 9616726]

93. Suzuki K, Bonner-Weir S, Hoi lister-Lock J, et al. Number and volume of islets transplanted in immunobarrier devices. Cell Transplantation. 1998; 71:47-52. [PubMed: 9489762]

94. Simeonovic CJ. Xenogeneic islet transplantation. Xenotransplantation. 1999; 6:1-5. [PubMed: 10355727]

95. Groth CG, Tibell A, Wenneberg L, et al. Clinical aspects and perspectives in islet xenotransplantation. Journal of Hepatobiliary Pancreatic Surgery. 2000; 7:364-369. [PubMed: 11180856]

96. Koike C, Friday RP, Nakashima I, et al. Isolation of the regulatory regions and genomic organization of the porcine $\alpha 1,3$-galactosyltransferase gene. Transplantation. 2000; 70:1275-1283. [PubMed: 11087141]

97. Koike C, Luppi P, Sharma SB, et al. Molecular basis for evolutionary loss of the agalactosyltransferase gene in higher primates. Journal of Biological Chemistry. 2002; 277:10114-10120. [PubMed: 11773054] 


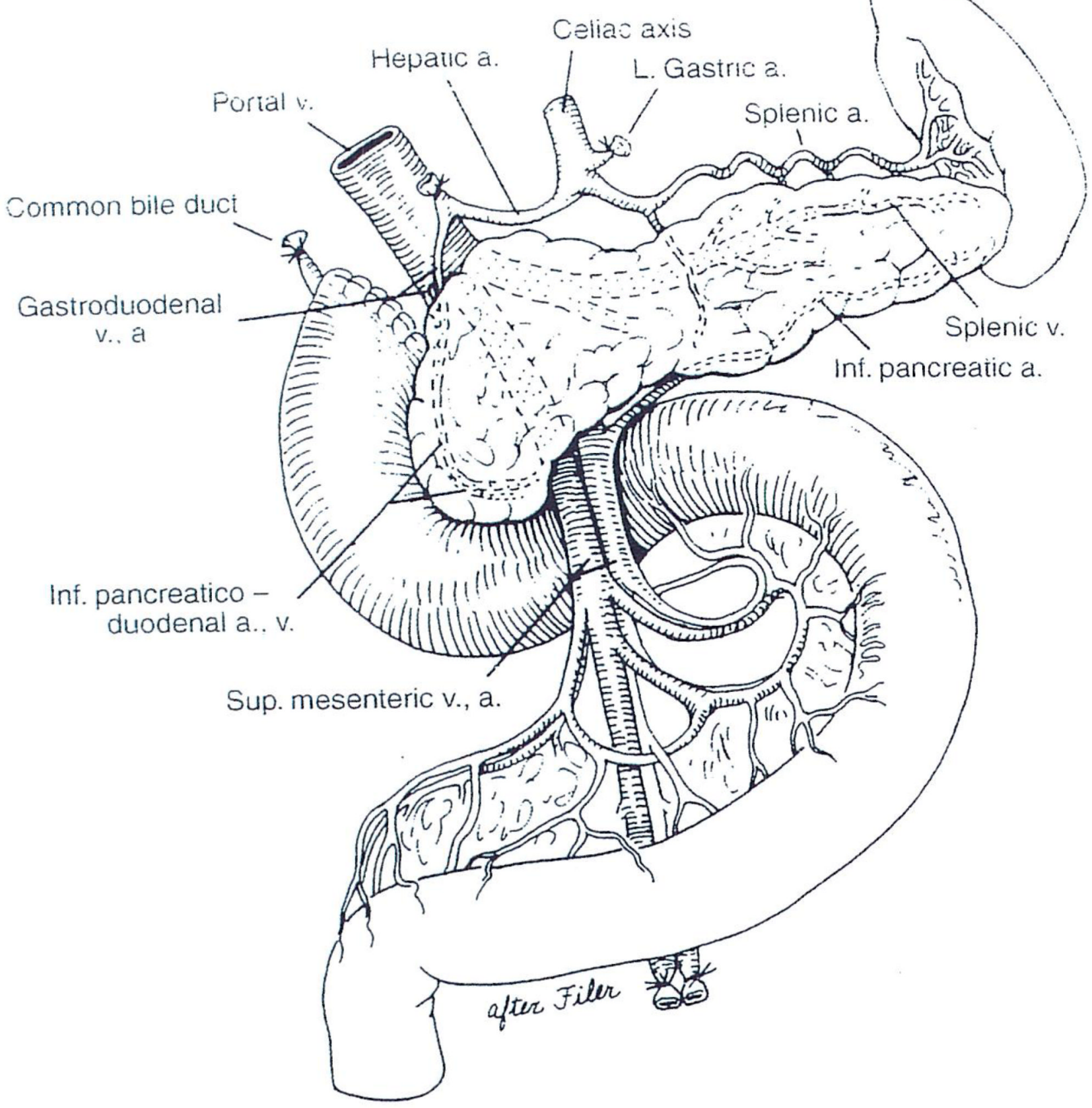

Figure 1.

Whole pancreas allotransplantation with exocrine secretion drainage directly into the host jejunum. 


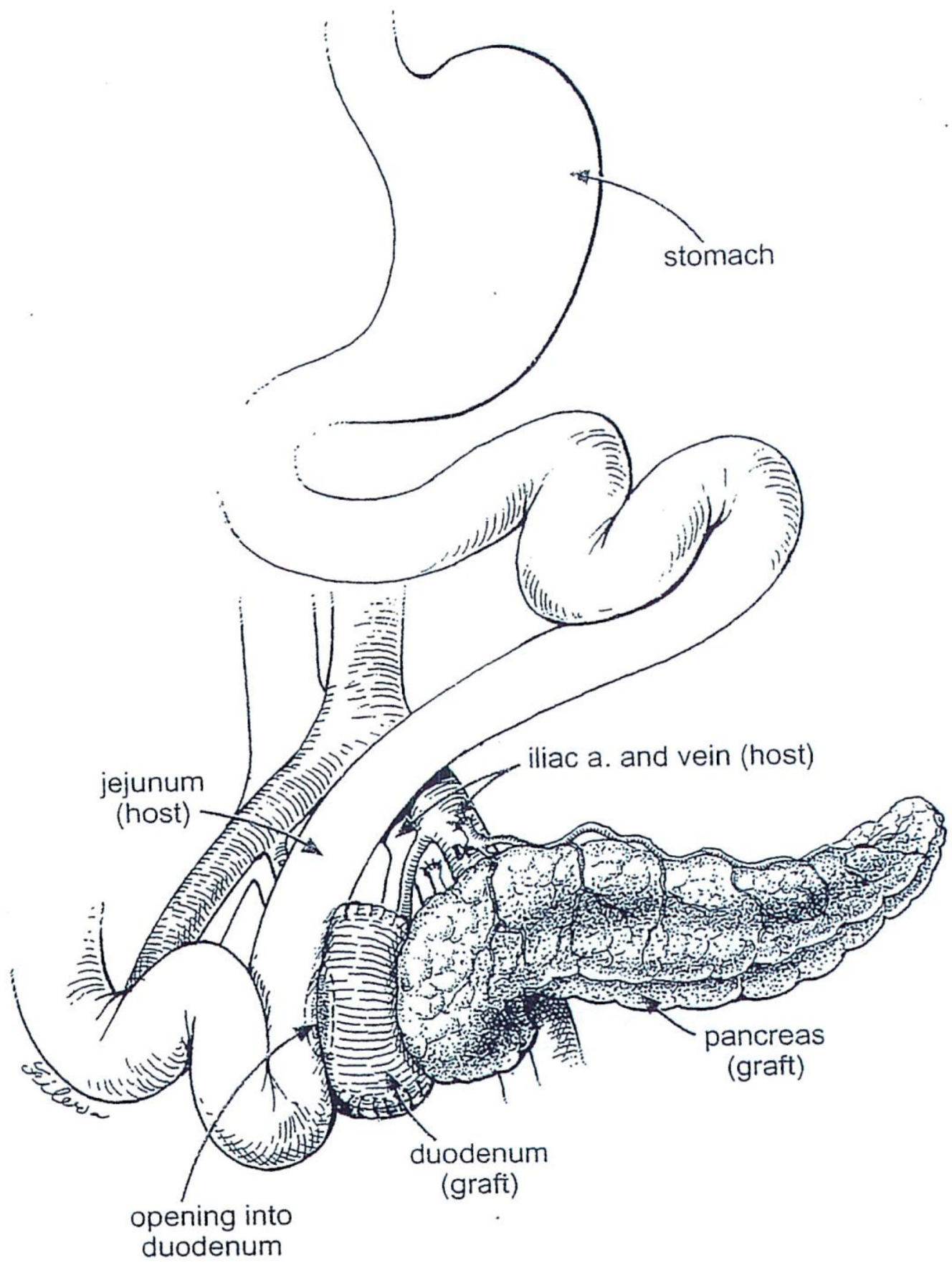

Figure 2.

Pancreatico-duodenal allotransplantation with exocrine secretion drainage into the host jejunum. 


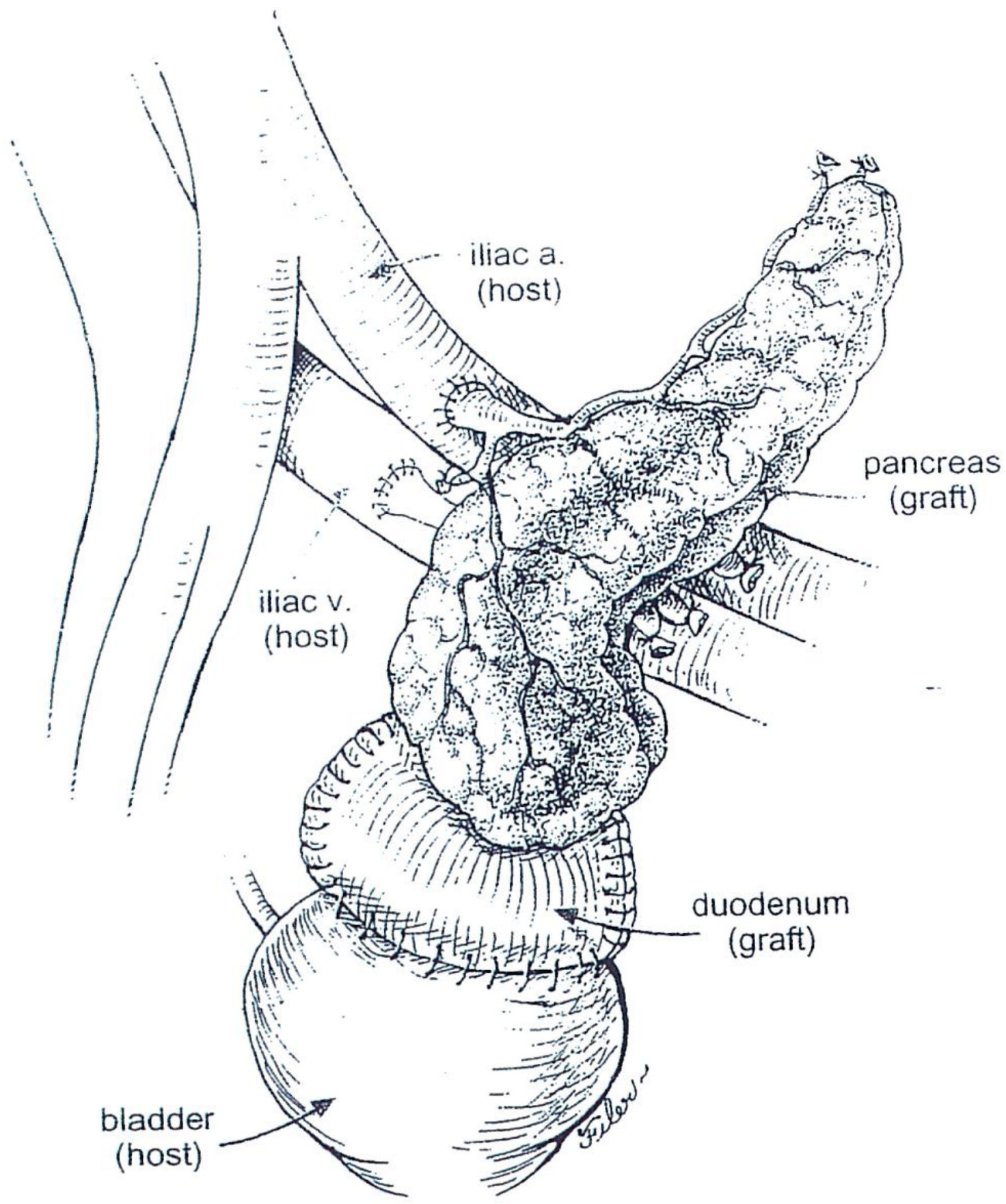

Figure 3.

Pancreatico-duodenal allotransplantation with exocrine secretion drainage into the host bladder. 


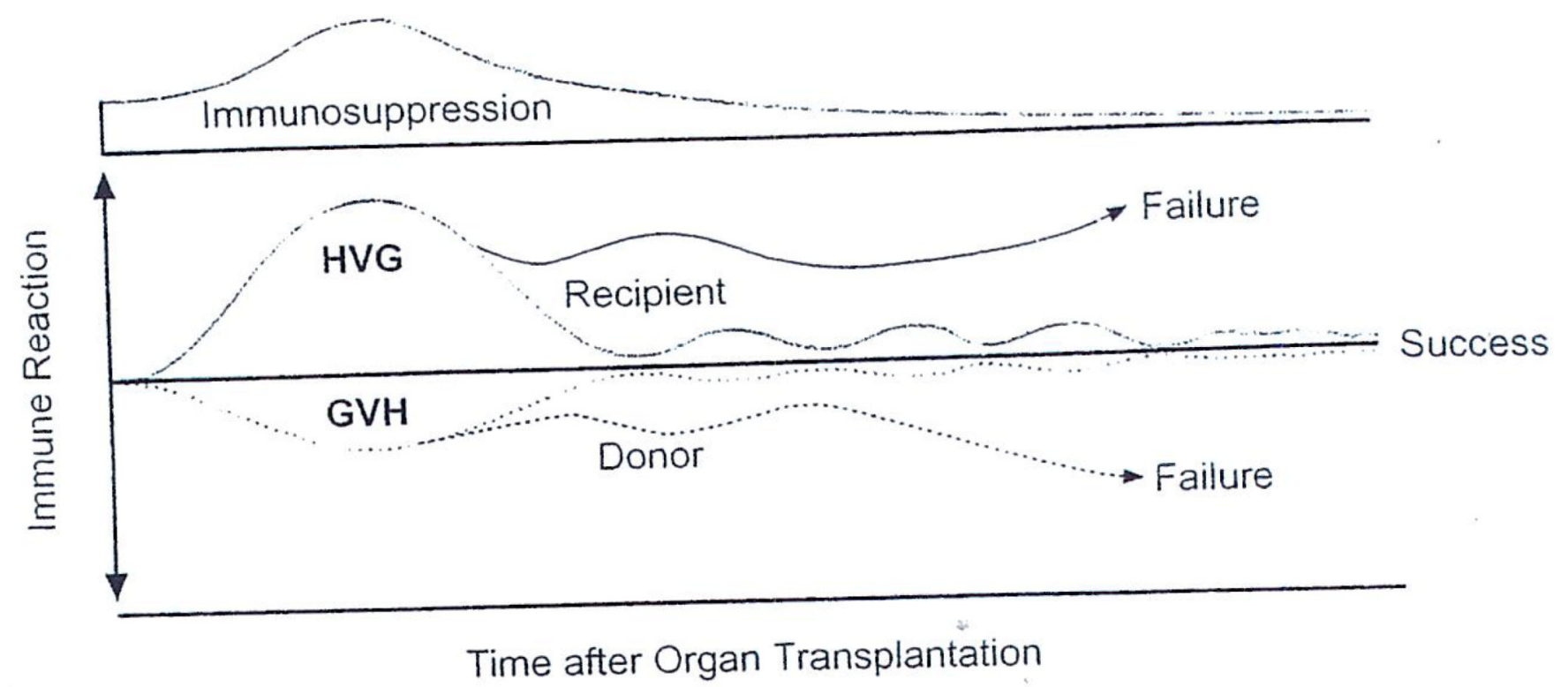

Figure 4.

Contemporaneous host-versus-graft (HVG) and graft-versus-host (GVH) responses following organ transplantation. Reproduced from Starzl TE and Zinkernagel RM (2001, Nature Reviews in Immunology 1: 233-239) with permission. 


\section{Pancreas Transplants Worldwide}

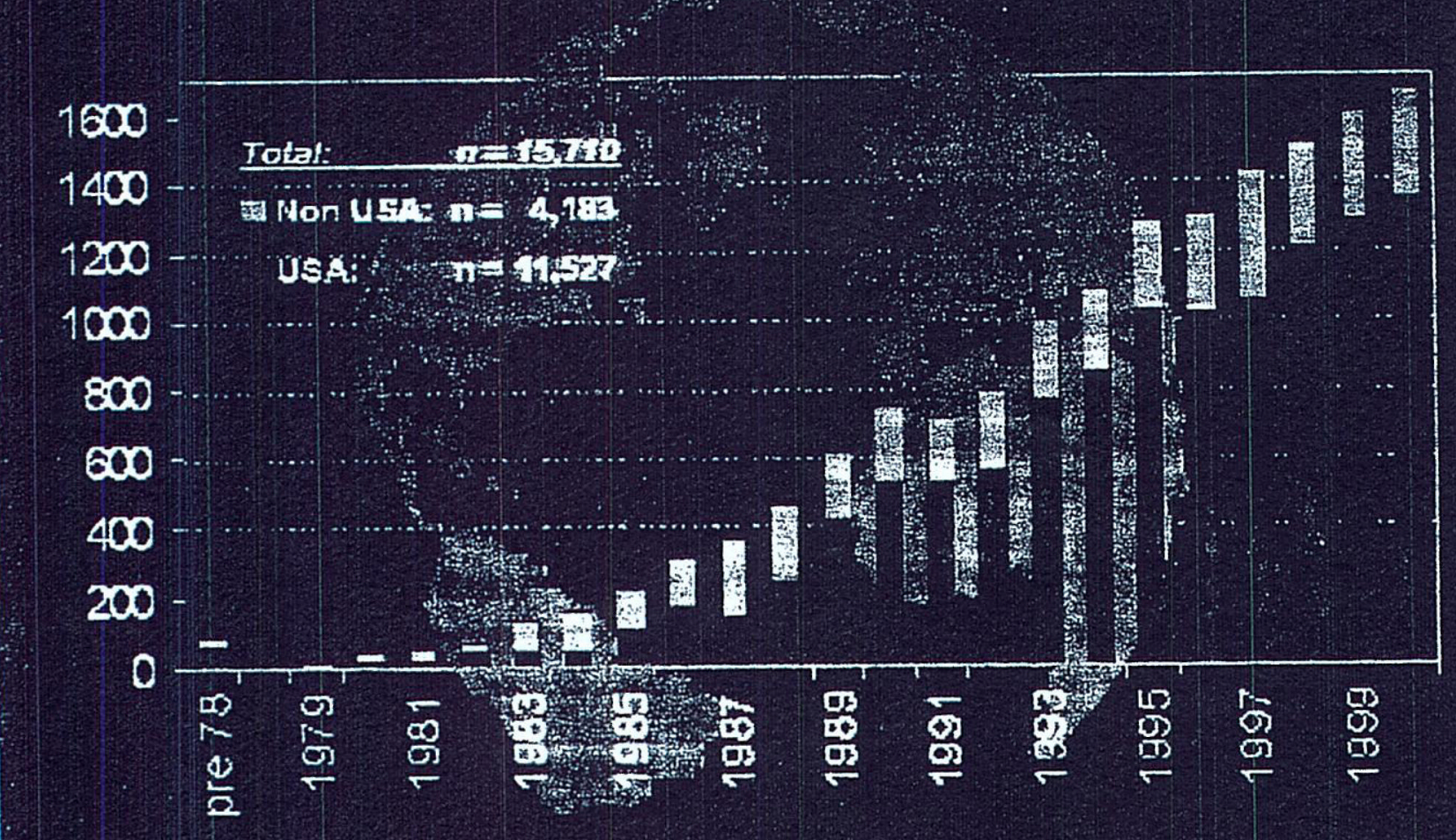

Figure 5.

Total number of pancreas transplants as reported by the International Pancreas Transplant Registry, as of August 2001. Reproduced from Newsletter 13(1), 2001, with permission from the International Pancreas Transplant Registry. 